\title{
Os Institutos Federais de Educação, Ciência e Tecnologia como Sistemas Sociais Autopoiéticos
}

\section{Federal Institutes of Education, Science and Technology as Autopoietic Social Systems}

\author{
Renato Avellar de Albuquerque (renato.albuquerque@poa.ifrs.edu.br) \\ UFRGS/IFRS
}

\author{
Michelle Camara Pizzato (michelle.pizzato@poa.ifrs.edu.br) \\ UFRGS/IFRS
}

\begin{abstract}
Resumo: O presente artigo apresenta uma abordagem do Instituto Federal de Educação, Ciência e Tecnologia do Rio Grande do Sul, como representativo do conjunto dos Institutos Federais (IFs), analisado sob a perspectiva da Teoria dos Sistemas Sociais, desenvolvido pelo sociólogo Niklas Luhmann, em sua função voltada à oferta e apoio ao ensino de ciências. Os autores buscam mostrar como os IFs se comportam enquanto um sistema autopoiético do tipo organizacional, tendo um de seus sentidos originais a tarefa de se tornar uma instituição de referência e excelência no ensino de ciências. Através da análise dos documentos normativos, das atas de colegiado de um curso de Licenciatura em Ciências da Natureza e de entrevistas, é possível identificar mecanismos de adaptação e atualização institucional. A conclusão aponta que o modelo teórico traduz as observações de funcionamento dos IFs e pode indicar como estes mecanismos transformam decisões e autorreferências em funções institucionais, traduzindo políticas públicas em práticas sociais.
\end{abstract}

Palavras-chave: Niklas Luhmann; políticas públicas; ensino de ciências; autopoiese.

Abstract: This article presents an approach from the Federal Institute of Education, Science and Technology of Rio Grande do Sul, as representative of the set of Federal Institutes (IFs), analyzed from the perspective of Theory of Social Systems, developed by the sociologist Niklas Luhmann, in his function focused on science teaching. The authors seek to show how IFs behave as an autopoietic system of the organizational type, having as one of their original meanings the task of becoming an institution of reference and excellence in science education. Through the analysis of the normative documents, the collegiate minutes of a Graduation in Natural Sciences, and interviews, it is possible to identify mechanisms for institutional adaptation and updating. The conclusion points out that the theoretical model translates the observations of the functioning of the IFs and can indicate how these mechanisms transform decisions and self-reference into institutional functions, translating public policies into social practices.

Keywords: Niklas Luhmann; public policy; science teaching; autopoiesis.

\section{INTRODUÇÃO}


Os Institutos Federais (IFs) são instituições criadas pela Lei Federal nº 11.892/2008, como resultado das transformações promovidas pelas políticas da Rede Federal de Educação Tecnológica, a partir do ano de 2005. Surgidos de um projeto nacional de desenvolvimento regional (VIDOR, 2015), os IFs resultam de combinações de identidades organizacionais, histórias, relações de poder e culturas escolares que produzem sua complexa dimensão institucional (ANDRADE, 2014). Se por um lado esta nova institucionalidade dos IFs apresenta uma diversidade de saberes e modos de atuação da educação, por outro representam desafios de operação e integração dos diversos campi que formam estas instituições (PERUCCHI; MUELLER, 2016).

Os IFs surgem como desdobramentos das visões educacionais expressas nas diretrizes do Plano de Desenvolvimento da Educação (PDE), ou seja, como parte de um amplo conjunto de reformas que iriam atingir todos os níveis da educação nacional, ainda na primeira década do século XXI, não só pelo investimento nas universidades, no ensino profissional e técnico, mas também no ensino médio e fundamental, como observado no Decreto $\mathrm{n}^{\circ}$ 6.094/2007, que dispõe sobre o Plano de Metas Compromisso Todos pela Educação (BRASIL, 2007_a).

Visando desenvolver novos modelos teóricos, com o objetivo de compreender estas organizações como sistemas integrados e complexos na promoção do desenvolvimento científico de base, foi explorado a utilização do conceito de sistemas sociais autopoiéticos, baseado na teoria do sociólogo Niklas Luhmann, na análise dos IFs, como modelos de organizações. A pesquisa sustenta que os IFs apresentam as características de organizações, tratadas por Luhmann, como sistemas que reproduzem decisões (LUHMANN, 1997), porém, formadas, ainda, por mecanismos que convertem as autorreferências basais, dos membros ou filiados, em autorreferências sistêmicas, atualizando o sentido dado ao ensino de ciências nestas instituições.

Através de pesquisa documental e de entrevistas, foi possível propor um modelo de interpretação sobre estes processos de funcionamento, atualização e transformação das práticas institucionais. Os documentos norteadores e atas de reunião de colegiado do curso permitiram a criação de uma representação dos espaços decisórios e como estes funcionam ao cumprir uma função de reprodução autopoiética da instituição, atualizando 
sentidos e funcionamentos sistêmicos, segundo as decisões formadas pelos vários espaços de poder.

A pesquisa apontou que os espaços de decisão, como colegiados, núcleos, conselhos, entre outros, são fundamentais no processo de atualização, pois possibilitam ampliar o número de informações possíveis a serem escolhidas e incorporadas como comunicações dentro do sistema. As informações, que podem ser problemas enfrentados, soluções e contingências, são inseridas nos espaços de decisões pelos membros da organização e podem se tornar temas a serem decididos e incorporados no conjunto comunicativo do sistema. Assim, a relação entre participação de membros e espaços decisórios impacta diretamente na capacidade de atualização e evolução institucional.

O objetivo da pesquisa foi o aprofundamento conceitual da abordagem de instituições de ensino científico, utilizando a teoria dos sistemas sociais aplicado aos IFs, como instrumento de análise diferenciado no âmbito dos estudos acadêmicos brasileiros, visando compreender os elementos de constituição de sua autoprodução, enquanto instituição autônoma e recente no cenário educacional brasileiro, além de possibilitar uma nova abordagem sobre o seu processo de desenvolvimento histórico.

\section{METODOLOGIA DE ANÁLISE}

O trabalho é resultado de uma pesquisa baseada em análise dos conteúdos, e aprofundamento conceitual teórico, proveniente dos registros de atividades de reunião e documentos norteadores da instituição (estatutos, planos, diretrizes). Estes foram analisados para compreender como o sentido original dos IFs transpassa da Lei Federal $\mathrm{n}^{\circ}$ 11.892/08 (BRASIL, 2008) para o interior do sistema social. Análises desse tipo podem apontar para as estruturas organizadoras ou processo de produção das semânticas representativas das práticas institucionais (BARDIN, 1979, p.214).

Os IFs são instituições que apresentam enormes vantagens para o desenvolvimento de estudos de cunho organizacional, relacionado ao ensino de ciências. Além de uma história mais recente, ao se considerar sua criação a partir da Lei Federal nº 11.892/2008, na qual acaba por conferir uma maior identidade à Rede Federal de Educação Profissional, Científica e Tecnológica, ao objetivar as finalidades dessas instituições e um 
modelo com diretrizes claras de organização e funcionamento. Além disso, a lei estabelece, claramente, sua intenção de se tornar centro de excelência na oferta do ensino de ciências e se qualificar como centro de referência no apoio à oferta do ensino de ciências, proporcionando capacitação técnica e atualização pedagógica aos docentes das redes públicas de ensino (BRASIL, 2008).

A padronização e estabilidade das operações sistêmicas são garantidas pelas normas e pelos procedimentos organizacionais, autorreferidas uma às outras, desde seu estatuto, passando ao Projeto Pedagógico Institucional (PDI), até chegar às ementas das disciplinas, as quais selecionam e restringem as amplas possibilidades de atuação do professor perante a formação do estudante, em meio à complexidade e à contingência existente nestas comunicações.

Entretanto, as dinâmicas institucionais criam sucessivos eventos que são constantemente tematizados, decididos e alterados, os quais ficam registrados em suas documentações, sejam normativos ou de memória institucional. Portanto, o estudo em fontes e registros institucionais podem apontar quais as decisões e os sentidos implícitos nas normatizações, resultado desta dinâmica de constante atualização, aqui chamada de autopoiese.

Para compreender essa instituição de forma mais estrita, foi escolhido o Instituto de Educação, Ciência e Tecnologia do Rio Grande do Sul (IFRS) como caso a ser investigado e, dentro dele, o Curso de Licenciatura em Ciências da Natureza: Biologia e Química (LCN) do Campus Porto Alegre para análise dos mecanismos autopoiéticos. Através da pesquisa em atas de reuniões de colegiado deste curso, foi produzida uma representação esquemática dos fluxos comunicativos que ocorrem nesse segmento institucional e como os espaços coletivos transformam autorreferência basal em autorreferência sistêmica, uma das características da autopoiese institucional.

A primeira etapa da pesquisa constituiu-se da preparação das informações a partir da pré-análise dos documentos, organizados como documentos norteadores (normativos) e como registros de decisões, especificamente as atas das reuniões de colegiado de curso da LCN, que formaram o corpus inicial da pesquisa. Após a leitura flutuante, e organização no software Nvivo 12, o material foi exaustivamente analisado em busca de 
elementos recorrentes para servirem de índices na criação de indicadores, os quais permitiriam uma codificação e uma abordagem dos materiais (SILVA; FOSSÁ, 2015).

A exploração do material, em especial das atas, permitiu a codificação, a classificação e a agregação de informações que produziram uma representação de categorias e fluxos de comunicação, o que poderíamos chamar de processo de unitarização. Seguindo as codificações a partir de critérios semânticos e sintáticos das atas foi possível criar uma representação dos fluxos da comunicação naquele espaço decisório (colegiado), a qual orientou um esquema explicativo combinado com os aspectos teóricos da teoria dos sistemas sociais de Niklas Luhmann.

A representação foi categorizada entre elementos e sistema, sendo os primeiros os "membros" e os tipos de informação inserida por eles, e os segundos o colegiado (como um mecanismo de circularidade autorreferencial do sistema) e a reprodução dos elementos do sistema, a comunicação de decisão, como efeitos de atualização de sentido e de autoprodução.

Após a seleção de alguns documentos mais representativos, algumas unidades de registro dessas atas foram analisadas de forma interpretativa para descrever como as relações teóricas estão expressas nestas documentações institucionais. Por último a interpretação desses dados foi realizada sobre a entrevista com o reitor do IFRS. Esta etapa surgiu após etapa de qualificação da pesquisa, com o objetivo de confrontar a análise dos documentos com outros instrumentos.

Um dos blocos da entrevista continha questões referente ao papel dos colegiados na atualização das funções institucionais, e a partir delas as categorias e os esquemas explicativos puderam ser comparados em busca de correspondências. O esquema é confrontado com elementos discursivos presentes na entrevista, evidenciando que impressões e observações realizadas com a prática e a experiência encontram lastro explicativo quando se analisa a instituição pelo viés teórico proposto na pesquisa. Eles podem desenvolver os elementos relacionais necessários para expandir a capacidade interpretativa da instituição com suas funções propostas como sentido de sua fundação e que convertem políticas públicas em transformações sociais.

\section{OS INSTITUTOS FEDERAIS, O IFRS, O CAMPUS E O CURSO}

Recebido em: 18/01/2021

Aceito em: 24/02/2021 
Os Institutos Federais de Educação, Ciência e Tecnologia (IFs) possuem como marco de criação a Lei Federal no 11.892/2008, a qual é referida pelos membros dessas instituições, muitas vezes, como "Lei de Criação". Este ato legal foi a culminância de um processo de transformação da Rede Federal de Educação Profissional, Científica e Tecnológica, concebida a partir de 2004, ainda na gestão de Tarso Genro à frente do MEC (AMORIM, 2013), e que passou por algumas etapas.

A primeira etapa foi o "destravamento legal", possível com a Lei Federal $n^{\circ}$ 11.195/2005 (BRASIL, 2005), que possibilitava ao governo federal investir na expansão da Rede Federal, sem a necessidade de parcerias com outros entes (SANGOI, 2019). A segunda etapa foi em 2007, com o Decreto 6.095/2007, que criava as diretrizes para o processo de integração de instituições federais de educação tecnológica, com o objetivo de constituir os Institutos Federais de Educação, Ciência e Tecnologia - IFET, no âmbito da Rede Federal de Educação Tecnológica (BRASIL, 2007_b).

Portanto, a chamada "Lei de Criação" é fruto de um processo de reestruturação das políticas da Rede Federal de Educação Tecnológica, integrado a um projeto nacional de desenvolvimento regional (VIDOR, 2015), que buscava atender tanto às expectativas de formação para a ciência e tecnologia, quanto às necessidades de formação para o mercado (BENTIN, 2014). Conforme bem observa Andrade (2014, p.18), os IFs não podem ser entendidos como mera mudança de designação em relação aos CEFETs, porém como um novo arranjo institucional, resultado da combinação de uma complexa gama de identidades organizacionais, culturas e histórias, além de objetivos bem delimitados e que não estava no horizonte das instituições predecessoras.

Foi justamente a posição de ambivalência entre sua nova institucionalidade e culturas organizacionais anteriores que criaram uma estrutura dotada de identidade e autonomia para o cumprimento de suas finalidades, em especial, como um centro de ensino de ciência e tecnologia (PERUCCHI; MUELLER, 2016). A partir das diretrizes do Plano de Desenvolvimento da Educação - PDE, em 2007, um conjunto de ações e programas foram apresentados para expansão e melhoria da educação, considerando que os IFs deveriam se constituir em centros de excelência na oferta de ensino de ciências e promover o ensino de ciências nas escolas públicas, mediante a formação de professores 
para a Educação Básica nas áreas de Química, Física, Biologia e Matemática (TAVARES, 2014, p.140).

O Instituto Federal de Educação, Ciência e Tecnologia do Rio Grande do Sul (IFRS), surge a partir da "Lei de Criação", em seu art. 5, constituído, inicialmente, pela integração do Centro Federal de Educação Tecnológica de Bento Gonçalves, da Escola Técnica Federal de Canoas e da Escola Agrotécnica Federal de Sertão e, ainda, no Anexo II, pela Escola Técnica da Universidade Federal do Rio Grande do Sul (UFRGS) e pelo Colégio Técnico Industrial Prof. Mário Alquati da Universidade Federal do Rio Grande (FURG), sendo a Reitoria do IFRS localizada na cidade de Bento Gonçalves, região da Serra Gaúcha (BRASIL, 2008).

A Escola Técnica da UFRGS, que em 2008 tinha uma história quase centenária, tornou-se o Campus Porto Alegre do IFRS e, com isso, inicia não apenas uma nova fase de sua expansão física e pedagógica, mas também uma nova função no cenário educacional, centrada na verticalização, de uma forma que não era possível quando estava vinculada à UFRGS (FONTOURA, 2018, p.50). Entre as possibilidades abertas, o Campus Porto Alegre poderia oferecer cursos de licenciatura, em razão das finalidades dos IFs, o que ao longo de 2009 acabou se consolidando como o Curso de Licenciatura em Ciências da Natureza: Biologia e Química (LCN).

O Curso de LCN foi o desdobramento de um processo histórico ligado ainda ao funcionamento da Escola Técnica da UFRGS, pois foi no ano de 1996 que ela passou a ofertar os cursos regulares de Técnico em Biotecnologia e Técnico em Química, além dos Cursos Pós-Técnicos de Controle e Monitoramento Ambiental (BRASIL, 2014), inaugurando uma infraestrutura física e de pessoal que iria constituir um dos aspectos da cultura institucional do campus.

No processo de transição institucional da antiga Escola Técnica da UFRGS para o Campus Porto Alegre do IFRS, os professores desses cursos passaram a vislumbrar novas possibilidades de atuação, não só em pesquisa e extensão, mas também na oferta de cursos de licenciatura. A construção inicial da proposta de duas licenciaturas, Química e Biologia, em certo momento de 2009, passou a convergir para um curso interdisciplinar que pudesse oferecer as duas habilitações (HECK, 2020). 
O curso de LCN passa a funcionar em 2010, tendo como justificativa as próprias diretrizes do MEC/SETEC ${ }^{1}$ sobre a expansão da Rede Federal e sua concepção sobre a finalidade dos IFs (BRASIL, 2010). A preocupação expressa no Projeto Pedagógico de Curso (PPC) quanto ao déficit de professores na Área de Ciência das escolas, principalmente as públicas, reflete, em parte, os objetivos maiores dos IFs, expressa em sua Lei de Criação, qual seja, tornar-se uma instituição que atende aos objetivos formação e apoio ao ensino de ciências. Porém, como interpretar a dinâmica de reprodução, adaptação e transformação desse sentido original dos IFs no ensino de ciência?

\section{OS INSTITUTOS FEDERAIS COMO SISTEMAS}

Tratar os IFs como sistemas sociais autopoiéticos despertou, em algumas ocasiões, certa surpresa aos que já tomaram contato com a Teoria Geral dos Sistemas Sociais (TGSS), do sociólogo Niklas Luhmann. Entretanto, quem a conhece sabe o quão controversa e complexa é a própria teoria, passando pela ambição de ser considerada uma fundação paradigmática na sociologia (LUHMANN, 2016, p.20), até seu princípio operativo comunicativo, anti-humanista, que transforma os sujeitos em sistemas (IZUZQUIZA, 2008, p.78).

A defesa sobre esta possibilidade de enquadramento teórico, a utilização do conceito de sistemas autopoiéticos, do tipo organizacional, para interpretar o funcionamento dos IFs, está melhor fundamentado em um dos nossos artigos, intitulado "Institutos Federais de Educação, Ciência e Tecnologia como Sistemas Sociais Autopoiéticos: uma interpretação de Luhmann", ainda em fase de submissão para uma revista. Porém, uma síntese dessa defesa parece ser necessária.

Luhmann propõe uma Teoria dos Sistemas Sociais como modelo explicativo da realidade, utilizando um conjunto de conceitos, muitas vezes adaptados de outros campos ou ressignificados, tendo a centralidade desse arcabouço teórico o conceito de sistemas (RODRIGUES; NEVES, 2017, p.27). O ponto de partida dessa análise está na diferença entre sistemas e ambiente, sendo o primeiro orientado pelo segundo, não só

\footnotetext{
${ }^{1}$ Secretaria de Educação Tecnológica do Ministério da Educação.
} 
adaptativamente, como também estruturalmente. Os sistemas se constituem e se mantêm pela produção e pela manutenção da diferenciação perante o ambiente (LUHMANN, 2016, p.33).

Para Luhmann, a diferenciação dos sistemas está ligada à redução da complexidade do ambiente, separado por um limite ou borda. Assim, a diferenciação é o princípio de formação dos sistemas, tanto para "fora" (sistemas/ambiente), quanto para "dentro" (sistema/subsistemas), que produz uma unidade, ou uma identidade (LUHMANN, 2016, p.35-36). É justamente a unidade dessa diferença, separada por um limite, que produz o fechamento operacional e a autorreferência sistêmica.

A autorreferência dos sistemas significa que os elementos, processos, partes, etc. estão voltados consigo (RODRIGUES; NEVES, 2017, p.42), sendo decorrência do seu sentido. O conceito de sentido é fundamental para entender a criação e manutenção dos sistemas e constitui como um fenômeno que produz uma pressão seletiva para a repetição de certas relações, uma disposição de remissões que aumenta as chances de determinado fenômeno se repetir no interior do sistema (LUHMANN, 2006, p.80-81).

Outro conceito importante nessa arquitetura teórica de Luhmann, a autopoiese, pode ser definida como a reprodução e autoprodução a partir de produtos próprios, portanto, não se trata somente de sistemas que se autorreferenciam, mas que se autoproduzem (RODRIGUES; NEVES, 2017, p.45). A teoria da autopoiese, criada pelos biólogos chilenos Humberto Maturana e Francisco Varela, como particularidade mais significativa dos organismos vivos, passou a ser adotada em diversos campos do conhecimento (IZUZQUIZA, 2008, p.110), e Luhmann o ressignificou como característica dos sistemas.

A teoria luhmanniana define quatro tipos de sistemas: não-vivos, vivos, psíquicos e sociais. Os sistemas sociais são divididos em interações, organizações e sociedade (LUHMANN, 2016, p.17). Desta maneira, as organizações, como um tipo de sistema social, são formadas pela associação de membros (elementos) que se baseiam em decisões. Para o autor, "os sistemas organizacionais são sistemas sociais constituídos por decisões e que atam decisões mutuamente entre si" (LUHMANN, 1997, p.14), ou seja, as organizações reproduzem a decisão de forma recursiva (autorreferencial) e promovem a 
atualização do sentido (diferenciação) através de comunicações de decisões, autopoieticamente.

Por isso, organizações como os IFs são autorreferenciais. O mecanismo de autorreferência e autopoiese fica claro ao analisar os documentos norteadores e as atas das reuniões de colegiado da $\mathrm{LCN}$, pois todos estes registros mostram como o sentido do sistema, objetivamente expresso na "Lei de Criação", é continuamente ressignificado através de decisões que se materializam em normatizações. As comunicações de decisões são os próprios elementos autoproduzidos continuamente na organização, atualizando todas as ações em direção ao desempenho das funções do sistema.

Os resultados parciais mostram que os objetivos institucionais dos IFs, ligados ao ensino de ciências, enquanto instituições de excelência e referência (BRASIL, 2008), são comunicados através dos documentos norteadores, pautando as funções desempenhadas nos cursos da instituição. Esta reprodução de objetivos, entendida pelo conceito de sentido, é um dos elementos centrais da constituição do sistema (MATHIS, 2004).

Os documentos do IFRS mostram que os sentidos institucionais possuem trânsitos no sistema de espaços decisórios que interconectam toda a instituição até as bordas do sistema onde a organização desempenha sua função. Entretanto, nestes espaços especializados, como os específicos de curso, há igualmente fluxos de comunicação fundamentais no processo de autopoiese, ao identificar conflitos entre as decisões e as operações, atualizando os repertórios de atuação institucional.

Nos parágrafos seguintes, iremos ilustrar como os sentidos do sistema transitam dos documentos norteadores aos documentos mais operacionais do curso e como, através do colegiado, as informações referentes ao funcionamento do curso são selecionadas, tematizadas de maneira autorreferencial e transformadas em referência sistêmica, inserindo-se na comunicação institucional como decisão, como elemento autoproduzido, responsável pela autopoiese institucional.

\section{RESULTADOS E DISCUSSÕES}

Conforme já abordado neste artigo, a análise partiu dos documentos norteadores do IFRS, desde a "Lei de Criação" até o PPC do curso de LCN, para evidenciar como o 
sentido do sistema perpassa toda a estrutura institucional, condicionando as ações para o cumprimento de suas finalidades de criação. Desta forma, a primeira etapa se constituiu em uma análise documental da instituição, a qual mostrou como esse sentido expresso na criação do IFRS se torna decisão reproduzida.

Esses sentidos, além de orientar as documentações formais da instituição, também acabam por sustentar as autorreferências institucionais nas comunicações dos espaços, principalmente, durante aquelas realizadas nos espaços decisórios. Isso ocorre porque ao se acolher uma informação e uma relação, partida de um elemento do sistema (membro da organização), o sistema o transforma em comunicação, passando a circular entre os demais membros em um processo de autorreferência sistêmica. Essa relação fica evidenciada no quadro abaixo:

Quadro 1 - Quadro com recortes sobre o sentido do ensino de ciências nos IFs, da Lei de Criação dos IFs até o Projeto Pedagógico de Curso.

\begin{tabular}{|c|c|}
\hline Documento & Redação \\
\hline Lei no $11.892 / 2008$ & 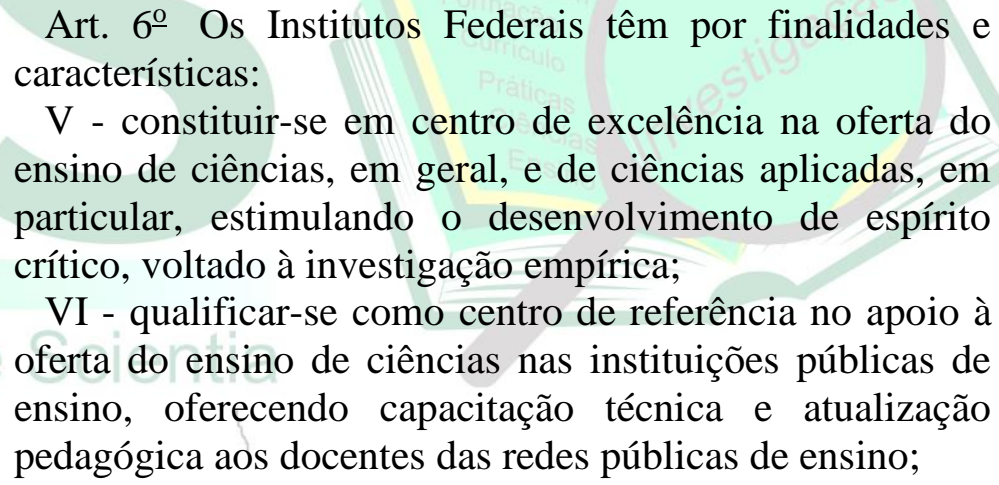 \\
\hline Estatuto do IFRS & $\begin{array}{l}\text { Art. } 4^{\circ} \text { O IFRS tem as seguintes finalidades e } \\
\text { características: } \\
\text { V - constituir-se em centro de excelência na oferta do } \\
\text { ensino de ciências, em geral, e de ciências aplicadas, em } \\
\text { particular, estimulando o desenvolvimento de espírito } \\
\text { crítico, voltado à investigação empírica e científica. } \\
\text { VI - qualificar-se como centro de referência no apoio à } \\
\text { oferta do ensino de ciências nas instituições públicas de } \\
\text { ensino, oferecendo capacitação técnica e atualização } \\
\text { pedagógica aos docentes das redes públicas de ensino; }\end{array}$ \\
\hline PDI - 2014-2018 & $\begin{array}{l}\text { 1.2.2 Visão Institucional } \\
\text { A Visão Institucional representa um estado futuro desejado } \\
\text { pela organização. Trata-se de um desafio que a instituição } \\
\text { deverá enfrentar e precisa representar algo a ser } \\
\text { conquistado, sendo, geralmente, atemporal. O IFRS }\end{array}$ \\
\hline
\end{tabular}




\begin{tabular}{|l|l|}
\hline & $\begin{array}{l}\text { realizou uma revisão de sua Visão Institucional e a nova } \\
\text { definição foi: } \\
\text { "Ser uma instituição de excelência em educação, ciência } \\
\text { e tecnologia." }\end{array}$ \\
\hline $\begin{array}{l}\text { PPC de } \\
\text { Licenciatura } \\
\text { Ciências } \\
\text { Natureza. }\end{array} \quad \begin{array}{l}\text { Isto implica a elaboração de um currículo para a } \\
\text { lacenciatura cuja concepção de educação seja aquela que } \\
\text { entendemos adequada para a formação dos nossos } \\
\text { licenciandos, futuros professores, e assim atender aos } \\
\text { objetivos da educação básica. } \\
\text { A formação de professores que se pauta nestas } \\
\text { premissas contribui para a excelência dos cursos } \\
\text { superiores, qualificando esses profissionais para a } \\
\text { atuação nos diferentes contextos da Educação Básica. } \\
\text { Uma questão central na construção de uma licenciatura } \\
\text { inovadora e diferenciada está na definição de uma } \\
\text { identidade própria que se articule com os sistemas de } \\
\text { ensino e com as escolas. }\end{array}$ \\
\hline
\end{tabular}

O quadro ilustra como os sentidos de criação do sistema são ressignificados a cada documento de referência institucional, os quais vinculam-se uns aos outros, porém sem alterar, significativamente, as relações expressas neste princípio. A preocupação em formar professores para a Educação Básica, em especial a pública, fica evidenciada em diversas passagens, em todos os documentos pesquisados, de forma bastante nítida.

A verificação dessa comunicação com as normas (decisões consolidadas e registradas), memórias sobre decisões pretéritas e relações entre premissas gera um processo de reflexão institucional, tornando a comunicação uma referência sistêmica. Esse processo ocorre através da seleção e da incorporação de informações, do sistema ou do ambiente, feita pelos elementos ao conjunto da comunicação dos demais participantes, momento em que essa circularidade de autorreferência, como reflexão, se transforma em referência sistêmica através da identificação de um "nós", distinto do "eles" ambiente. Este mecanismo transforma as referências dos elementos, enquanto membros individuais, em autorreferência sistêmica, pertencente à instituição.

Quadro 2 - Trechos de atas de reunião de colegiado do curso de LCN, que ilustram como as comunicações realizadas a partir de autorreferências basais se convertem, após a comunicação destes espaços, em ações/projeções realizadas por representante institucional, em nome do curso.

Ata 02/2014 "A representante discente da turma 6, Discente 1, solicitou a alteração de sala na sede Ramiro por conta da posição do quadro 


\begin{tabular}{|l|l|}
\hline \multirow{1}{*}{ Ata 06/2014 } & $\begin{array}{l}\text { verde [...] A coordenadora de curso se prontificou a entrar em } \\
\text { contato com os responsáveis por reservas de salas [...]" }\end{array}$ \\
& $\begin{array}{l}\text { "A representante discente da turma LCN7, Discente 2, encaminhou } \\
\text { solicitação de sete alunos do curso interessados em cursar a } \\
\text { componente curricular [...] A coordenadora de curso encaminhará } \\
\text { a solicitação à Área de Ciências Exatas, Química e Tecnologia dos }\end{array}$ \\
$\begin{array}{l}\text { Alimentos para verificação de carga horária e de disponibilidade de } \\
\text { professores." }\end{array}$ \\
\hline Ata 07/2014 & $\begin{array}{l}\text { "Discutiu-se, a partir de uma intervenção da representante discente } \\
\text { Discente 3, a possibilidade de recebimento de livros didáticos } \\
\text { doados por escolas públicas e se encaminhou à verificação da base } \\
\text { legal para este procedimento." }\end{array}$ \\
\hline
\end{tabular}

O quadro anterior, com extratos de atas de colegiado do curso de LCN, mostra como a solicitação (informação) de um ou mais membros, ao ser acolhido pelo colegiado, passa por um processo autorreferencial (comunicação) que avalia e encaminha esta referência basal, portanto, decide, convertendo-se em manifestação formal do curso, institucional (sistêmica), ao passar a ser realizado pela coordenação em nome do curso. Isso ilustra o mecanismo de transformação das autorreferências dentro do sistema e que, em última análise, produz seus próprios elementos constitutivos, pois o sistema organizacional irá se caracterizar pelas ações produzidas em nome das funções institucionais, decididas pelos espaços decisórios de legitimação.

A seguir apresentamos a figura que ilustra o esquema das conversões das autorreferências basais em autorreferências sistêmicas, através do fluxo de comunicação realizada nas atas de colegiado. Seguindo uma análise experimental, baseada na lógica exposta por Moraes (1999, p.14), que aponta como a análise de documentos vem sendo categorizada historicamente pela classificação proposta por Laswell, partindo de seis questões (1- Quem fala?; 2- Para dizer o quê?; 3- A quem?; 4- De que modo?; 5- Com que finalidade?; 6- Com que resultados?), propomos a seguinte esquematização: 


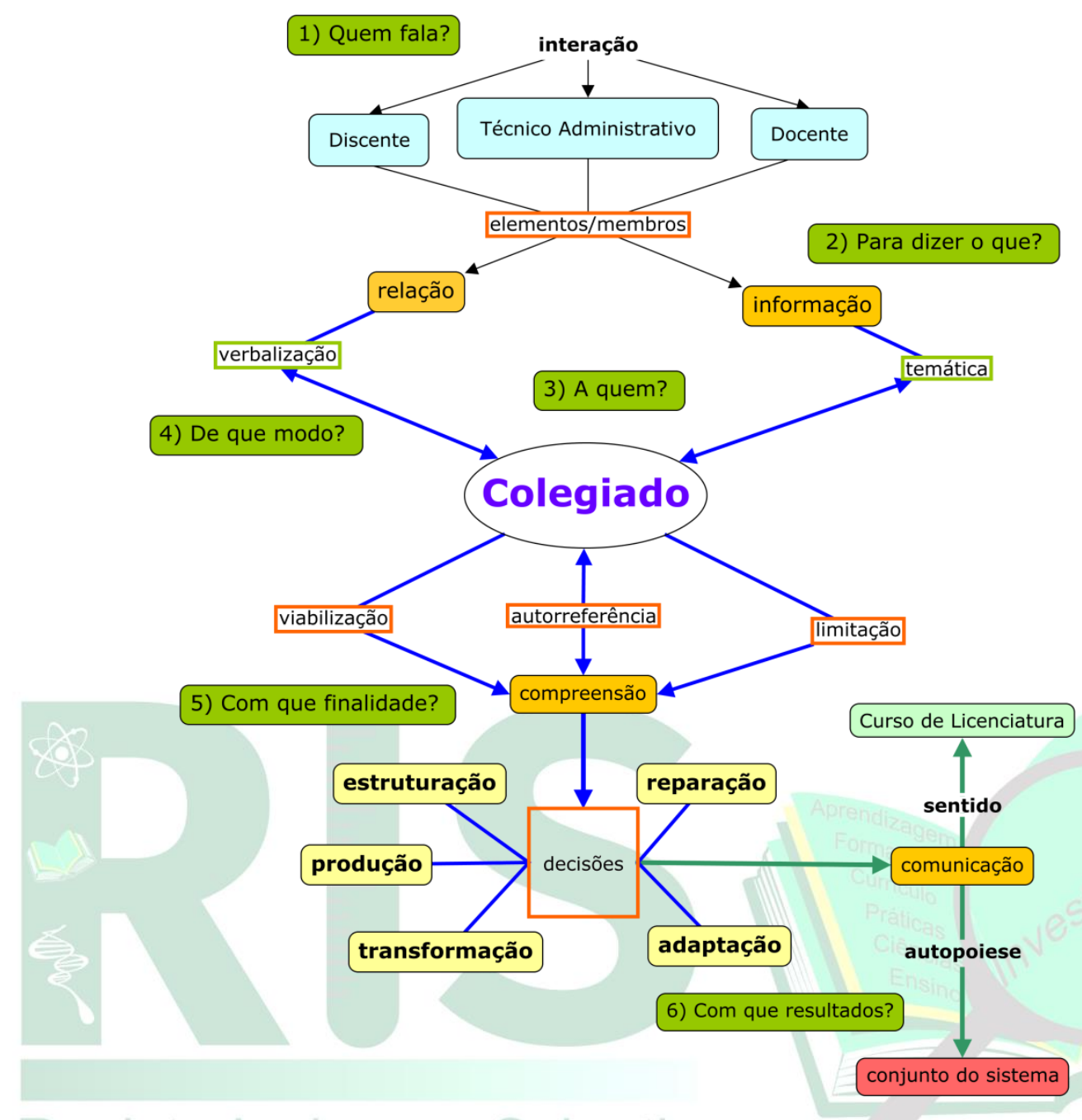

Figura $1-$ Representação do mecanismo de conversão das autorreferências em uma reunião de colegiado. (Elaboração dos autores)

A figura ilustra o mecanismo pelo qual as autorreferências basais, comunicadas pelos membros do sistema (segmentos), transformam-se em autorreferência sistêmica, ao converter as informações sobre temas (currículo, infraestrutura, eventos, pesquisas, etc), inseridos por determinada relação (por um verbo que o qualifica, como propor, questionar, acolher, solicitar, etc) em decisões que atualizam o sentido funcional do sistema ou insere novo elemento no conjunto do sistema que o possibilita se autoproduzir a partir de novas decisões.

O esquema explicativo proposto pode proporcionar uma nova forma de interpretar os fenômenos de funcionamento institucional. Ao confrontar este esquema com as percepções de membros da instituição, podemos compreender que a participação 
democrática nos espaços decisórios não constitui apenas um princípio de valor, mas também um elemento essencial para a atualização e adaptação institucional.

Em entrevista, ao ser perguntado sobre sua opinião em relação ao impacto da reunião de colegiado na instituição, o reitor do IFRS, professor Júlio Xandro Heck, respondeu da seguinte forma:

\begin{abstract}
O que eu sempre notei como diretor de ensino: curso que se reúne bastante, com bastante frequência, tem menos problema que curso que não se reúne, isso é notório, e esse é um olhar de observador de quatro anos, de diretor de ensino, curso que tem coordenador presente, que se chama todo mundo, que conversa, que o aluno é ouvido no seu dia a dia, nas suas angústias, chega menos problemas para o diretor de ensino, e por consequência, os problemas são resolvidos de forma mais céleres e de forma mais simples, então reuniões frequentes de colegiados, com uma boa métrica de organização, elas facilitam a mecânica da instituição, isso para qualquer curso, eu não tô falando nem para a LCN ou curso superior, vale para tudo (HECK, 2020). (grifo dos autores).
\end{abstract}

O relato do gestor da instituição corresponde à observação sobre o funcionamento institucional e sua relação com a participação democrática. Porém, o vínculo estabelecido, entre reunião e redução de problemas, pode ser explicado justamente pelo mecanismo autopoiético representado anteriormente. A maior frequência de seleção de informações, autorreferenciais ao sistema, pois relativas às funções institucionais, comunicadas no interior desse mesmo sistema, transformam-se em comunicações de decisões que ajustam o sentido organizacional ou alimentam o próprio sistema para novas decisões, sem que se chegue ao limite de conflitos entre os membros/filiados da organização.

Entretanto, cabe ressaltar que a participação de todos os segmentos é de especial valor nessa observação. Aquilo que é explicado como "ouvir as angústias", sob a forma de relato dos professores e gestores, na explicação teórica, transforma-se em "ampliação da capacidade de seleção das informações pelo sistema" já que, tendo uma tendência autorreferencial, os mecanismos sistêmicos não teriam a capacidade de dar sentido à algumas informações selecionadas. Logo, informações que não se transformam em comunicação aparecem como "ruídos" não interpretáveis ao sistema. Neste sentido, a expressão utilizada pelo reitor "facilitam a mecânica da instituição" não poderia estar mais afinada a tal abordagem teórica.

E ainda, perguntado se estes espaços decisórios são um problema ou uma solução para a instituição, o reitor respondeu: 
Para mim, são órgãos necessários, em primeiro lugar, e legítimos e essas esferas... E aí tem um outro lado, que a gente não vê e passa desapercebido, é bom para o gestor ter órgãos colegiados para decidir junto, né, torna mais lento às vezes, não sai do jeito que a gente gostaria, mas é do processo e a decisão não é tua, não é tua coordenador de curso, não é tua diretor de campus, não é tua reitor sozinha, né, são decisões que eu acho que solidificam, e decisões importantes, e de grande repercussão que, eu sempre acho, que elas têm que ser legitimadas nas várias instâncias, a seu nível, uma decisão que impacte no curso da LCN, ela tem que ser legitimada pelo colegiado, uma decisão que impacta no Campus Porto Alegre, em todos os cursos, ela tem que seja legitimado no Conselho de Campus, uma decisão que repercute no IFRS com um todo tem que ser legitimada no seu Conselho Superior (HECK, 2020). (grifo dos autores).

Esta passagem acima ilustra como o gestor entende a relação entre "órgãos colegiados" e "legitimação" que, se abordado segundo a instrumentalização teórica, estaria ligado ao processo de conversão das autorreferências basais em autorreferências sistêmicas. A autorreferência basal é quando as diferenciações entre elemento e relação estão na base de operação, é uma comunicação autorreferente, mas ainda não sistêmica. A reflexividade (autorreferência processual) coloca em sua base a diferenciação entre o antes e o depois, por meios de expectativas de reação e reação às expectativas, pretendendo a formação de uma unidade que sintetiza uma pluralidade de elementos (LUHMANN, 2006, p.502-503). Mas é somente na reflexão (autorreferência sistêmica) que este processo irá se completar, quando a comunicação se "legitima" a ponto de ser designada como "o curso", "o campus", "a instituição".

Esse processo pode ser visto, mais nitidamente, na forma como o gestor lida com as relevâncias de informações e decisões que, de maneira similar, responde ao mesmo processo de legitimação ou de autorreferência. Quando perguntado sobre o processo de seleção e de atribuição de relevância das informações que chega a ele, como reitor, para serem decididas ou intervidas, ele respondeu:

\footnotetext{
Volta a origem da tua pergunta, da questão dos órgãos colegiados, é uma fonte sempre de informação, e eu usei a palavra antes para ti, de demanda, eu, enquanto reitor, eu sempre tento na hierarquia de demandas [atender] as demandas que sejam coletivas, que venham organizadas de coletivos, seja eles quais forem, um curso, um coletivo de um núcleo, a gente tem vários núcleos no IFRS, o coletivo de diretores, é um coletivo importante (HECK, 2020). (grifo dos autores).
}

Novamente fica clara a relação entre o processo de autorreferência que as comunicações assumem no interior da instituição. Isso se relaciona à capacidade de seleção das informações circulantes no sistema. Conforme já dito, informações não 
selecionadas e aceitas não se transformam em comunicação e, neste caso, configuram meros ruídos para o sistema.

A partir da compreensão desse mecanismo é possível perceber que a autoprodução de uma instituição, que tem como sentido sistêmico o "tornar-se centro de referência e de excelência no ensino de ciências" passa, fundamentalmente, pelos espaços coletivos de decisão, que transformam as autorreferências do sistema no reforço de seu sentido. Esta compreensão leva ao destaque em relação à função da participação democrática nas organizações de ensino de ciência como instrumento de autoformação dos participantes da instituição e como estratégia para a seleção de informações do ambiente.

A possibilidade de inserção e participação de membros do sistema que transitam próximo ao seu limite institucional, considerando que discentes possuem menor vínculo cronológico e de responsabilidade profissional com a instituição, constitui uma estratégia fundamental para a seleção de informações e sua introdução no sistema como forma de complexificar sua organização e sua atuação. Tais mecanismos são essenciais para o acoplamento com outras instituições de ensino de ciências, como as escolas de ensino fundamental ou secretarias de educação, as quais devem auxiliar não só na qualificação, mas também na função de apoio aos arranjos produtivos locais como forma de atender aos objetivos pelos quais os IFs foram criados.

\section{CONCLUSÕES}

A finalidade do estudo é ajudar na compreensão sobre o ensino de ciências no país a partir do funcionamento dos IFs. A abordagem sistêmica visa auxiliar no entendimento sobre os processos internos de autopoiese que produzem, atualizam e transformam as operações e as funções institucionais, permitindo a construção desse sentido institucional.

A abordagem relatada mostrou que o processo autopoiético reproduz e atualiza continuamente o ensino de ciências nos IFs, ao decidir sobre as formas de atuação à luz dos seus sentidos de criação e sua autorreferência. A participação de variados elementos em espaços de decisão possibilita a seleção de informações e as referências do sistema e do próprio ambiente, os quais, pelo processo de reflexão, selecionam e decidem quais comunicações e quais informações são mantidas ativas, as que se modificam e as que são 
suprimidas dos fluxos comunicativos institucionais. Embora a pesquisa tenha se restringido a análise sobre o colegiado de curso, este processo autopoiético ocorre nos diversos espaços comunicativos, participativos e decisórios da instituição.

O processo formativo nesta nova institucionalidade não se reduz às operações pedagógicas do ensino como função do sistema. A abordagem sistêmica ajuda a compreender que as vivências e as incorporações de sentidos, de identidades e de autorreferências, como meio de operação do sistema, são fundamentais para o pertencimento dos estudantes ao universo científico e tecnológico ao qual os IFs têm a missão de produzir. Os aspectos de organização e de atuação nos sistemas sociais são elementos formativos essenciais para a constituição profissional dos estudantes dos IFs, pois trata-se de base para a compreensão da ciência, das instituições científicas e de sua atuação na sociedade.

\section{REFERÊNCIAS}

AMORIM, Mônica Maria Teixeira. A organização dos Institutos Federais de Educação, Ciência e Tecnologia no conjunto da educação profissional brasileira. 245 f. 2013. Tese (Doutorado em Educação) - Universidade Federal de Minas Gerais, Belo Horizonte, MG, Brasil, 2013.

ANDRADE, Andréa de Faria Barros. Os Institutos Federais de Educação, Ciência e Tecnologia: Uma Análise de Sua Institucionalidade. 2014. 209f. Tese (Doutorado em Educação) - Universidade de Brasília/UnB, Brasília, 2014.

BARDIN, Laurence. Análise de Conteúdo. Lisboa, Edições 70, 1979.

BENTIN, Priscila Caetano. A criação dos Institutos Federais de Educação, Ciência e Tecnologia e sua proposta de ensino superior. 124 f. 2014. Dissertação (Mestrado em Educação) - Universidade Federal do Estado do Rio de Janeiro (UNIRIO), Rio de Janeiro, RJ, Brasil, 2014.

BRASIL. Decreto no 6.094, de 24 de abril de 2007. Dispõe sobre a implementação do Plano de Metas Compromisso Todos pela Educação, pela União Federal, em regime de colaboração com Municípios, Distrito Federal e Estados, e a participação das famílias e da comunidade, mediante programas e ações de assistência técnica e financeira, visando a mobilização social pela melhoria da qualidade da educação básica. Diário Oficial da União, Poder Legislativo, Brasília, DF, 25 abr. 2007_a.

BRASIL. Decreto n⿳ 6.095, de 24 de abril de 2007. Estabelece diretrizes para o processo de integração de instituições federais de educação tecnológica, para fins de constituição 
dos Institutos Federais de Educação, Ciência e Tecnologia - IFET, no âmbito da Rede Federal de Educação Tecnológica. Diário Oficial da União, Poder Legislativo, Brasília, DF, 25 abr. 2007_b.

BRASIL. Lei $n^{\circ} 11.195$, de 18 de novembro de 2005. Dá nova redação ao $\S 5^{\circ}$ do art. $3^{\circ}$ da Lei n ${ }^{\circ} 8.948$, de 8 de dezembro de 1994. Oficial da União, Poder Legislativo, Brasília, DF, Edição Extra, 18 nov. 2005.

BRASIL. Lei $\mathbf{n}^{\circ}$ 11.892, de 29 de dezembro de 2008. Institui a Rede Federal de Educação Profissional, Científica e Tecnológica, cria os Institutos Federais de Educação, Ciência e Tecnologia, e dá outras providências. Diário Oficial da União, Poder Legislativo, Brasília, DF, 30 dez. 2008

BRASIL, Instituto Federal de Educação, Ciência e Tecnologia do Rio Grande do Sul Reitoria. Plano de Desenvolvimento Institucional 2014-2018. Bento Gonçalves, 2014. Disponível em: https://ifrs.edu.br/wp-content/uploads/2020/07/pdi-2014_2018.pdf. Acesso em: 10 ago. 2020.

BRASIL. Ministério da Educação/SETEC, Instituto Federal de Educação, Ciência e Tecnologia do Rio Grande do Sul - Campus Porto Alegre. Projeto Pedagógico Licenciatura em Ciências da Natureza: Habilitação em Biologia e Química, 2010. Disponível em: http://www.poa.ifrs.edu.br/images/Cursos/Superiores/Licenciatura Ciencias_Natureza_Biologia_Quimica/ppc_ciencias_natureza_ago2013.pdf. Acesso em: 13 ago. 2020.

FONTOURA, Julian Silveira Diogo de Ávila. A gestão da educação superior em contextos emergentes: a perspectiva dos coordenadores dos cursos superiores de tecnologia do IFRS - Campus Porto Alegre. 204 f. 2018. Dissertação (Mestrado em Educação) - Pontifícia Universidade Católica do Rio Grande do Sul, Porto Alegre, RS, Brasil, 2018.

HECK, Júlio Xandro. [Entrevista]. Porto Alegre-Canoas, novembro, 2020.

IZUZQUIZA, Ignacio. La sociedad sin hombres: Niklas Luhmann o la teoría como escándalo. 2a edicióned. Rubí (Barcelona): Anthropos Editorial, 2008.

LUHMANN, Niklas. Organización y decisión. Autopoiesis, acción y entendimiento comunicativo. México: Anthropos, 1997.

LUHMANN, Niklas. La sociedad de la sociedad. Ciudad del México: Editorial Herder, 2006.

LUHMANN, Niklas. Sistemas Sociais: esboço de uma teoria geral. Petrópolis, RJ: Vozes, 2016.

MATHIS, Armin. A sociedade na teoria dos sistemas de Niklas Luhmann Sociedade como sistema. In: Presença Revista de Educação, Cultura e Meio Ambiente, v.8, n.28, 
p. 1-22, maio, 2004.

MORAES, Roque. Análise de Conteúdo. In: Revista Educação, v. 22, n. 37, Porto Alegre, p. 7-32, 1999.

PERUCCHI, Valmira;; MUELLER, Suzana Pinheiro Machado. Produção de conhecimento científico e tecnológico nos Institutos Federais de Educação, Ciência e Tecnologia: uma investigação sobre a sua natureza e aplicação. In: Perspectivas em Ciência da Informação, v.21, n.1, p.134-151, jan./mar. 2016.

RODRIGUES, Léo Peixoto; NEVES, Fabrício Monteiro. A sociologia de Niklas Luhmann. Coleção Soed. Petrópolis, RJ: Vozes, 2017.

SANGOI, Paulo Roberto. A transformação da Escola Técnica da Universidade Federal do Rio Grande do Sul em Campus Porto Alegre do Instituto Federal do Rio Grande do Sul: uma nova institucionalidade e um novo modelo de educação profissional e tecnológica. 129 f. 2019. Tese (Doutorado em Educação em Ciências) - Universidade Federal do Rio Grande do Sul (UFRGS), Porto Alegre, 2019.

SILVA, Andressa Hennig; FOSSÁ, Maria Ivete Trevisan. Análise de conteúdo: exemplo de aplicação da técnica para análise de dados qualitativos. In. Qualit@s Revista Eletrônica, [s. 1.], v. 17, n. 1, p. 1-14, 2015. Disponível em: http://revista.uepb.edu.br/index.php/qualitas/article/view/2113/1403

TAVARES, Moacir Gubert. A constituição e a implantação dos Institutos Federais no contexto da expansão do Ensino Superior no Brasil: o caso do IFC - Campus Rio do Sul. 2014, 315f. Tese (Doutorado em Educação) - Univesidade Estadual de Ponta Grossa, Ponta Grossa, 2014.

VIDOR, Alexandre Martins. Educação Profissional e Tecnológica: a Contribuição do Instituto Federal do Rio Grande do Sul no Desenvolvimento de Viamão (RS). 2015, 64f. Dissertação (Mestrado em Economia) - Universidade do Vale do Rio dos Sinos (UNISINOS), São Leopoldo, 2015. 